\title{
The Investigation of Anti-Proliferative Effects of [Ag2(sac)2(dap)2] Complex on Different Types of Cancer
}

\author{
Serkan Güney ${ }^{1}$, Sercan Ergün ${ }^{2}$, Ivana Matic ${ }^{3}$, Nina Petrovic ${ }^{4}$, Tatjana Stanojkovic ${ }^{5}$ \\ ${ }^{1}$ Department of Chemistry and Chemical Processing Technologies, Ulubey Vocational Higher School, Ordu University, Ulubey, \\ Ordu, Turkey, \\ ${ }^{2}$ Department of Medical Biology, Faculty of Medicine, Ordu University, Altınordu, Ordu, Turkey \\ ${ }^{3}$ Institute of Oncology and Radiology of Serbia, Pasterova 14, Belgrade, Serbia \\ ${ }^{4}$ Vinča Institute of Nuclear Sciences, University of Belgrade, Mike Alasa 12-14, Belgrade, Serbia \\ ${ }^{5}$ Institute of Oncology and Radiology of Serbia, Pasterova 14, Belgrade, Serbia
}

Received: 19 Februvary 2020, Accepted: 05 April 2020, Published online: 30 April 2020

(C) Ordu University Institute of Health Sciences, Turkey, 2020

\begin{abstract}
Objective: Cytotoxic features of silver and saccharine compounds have taken attention due to the fact that most of them have showed a cytotoxic effect against tumor cells. In this study, it is aimed to investigate antiproliferative effects of [Ag2(sac)2(dap)2] complex on different types of cancer cell lines.

Methods: HeLa (cervical cancer), PC-3 (prostate cancer), DU-145 (prostate cancer), A549 (non-small cell lung cancer), K562 (chronic myeloid leukemia) and MRC-5 (normal lung fibroblast) cell lines were grown in plates. In order to determine anti-proliferative effects, IC 50 values of [Ag2(sac)2(dap)2] and cisplatin on these cell lines were determined by MTT method.

Results: IC 50 value of [Ag2(sac)2(dap)2] complex was $19.53 \pm 1.74 \mu \mathrm{M}$ for HeLa cell line, $17.14 \pm 1.41$ $\mu \mathrm{M}$ for PC-3 cell line, $18.56 \pm 4.04$ for DU 145 cell line, $17.93 \pm 1.06 \mu \mathrm{M}$ for A549 cell line, $3.18 \pm 0.04 \mu \mathrm{M}$ for $\mathrm{K} 562$ cell line and $7.25 \pm 1.00 \mu \mathrm{M}$ for MRC-5 cell line. Also, IC 50 value of cisplatin was $4.00 \pm 0.47$ $\mu \mathrm{M}$ for HeLa cell line, $12.29 \pm 1.60 \mu \mathrm{M}$ for PC-3 cell line, $5.05 \pm 0.65$ for DU 145 cell line, $12.74 \pm 1.26 \mu \mathrm{M}$ for A549 cell line, $5.90 \pm 0.59 \mu \mathrm{M}$ for K562 cell line and $5.91 \pm 0.32 \mu \mathrm{M}$ for MRC-5 cell line. Only in K562 cell line, IC 50 of [Ag2(sac)2(dap)2] complex was lower than IC 50 of cisplatin.

Conclusion: Anti-proliferative activity of [Ag2(sac)2(dap)2] complex is more than cisplatin on chronic myeloid leukemia cells so this complex may be possible to be used as a treatment option especially for chronic myeloid leukemia.
\end{abstract}

Key words: [Ag2(sac)2(dap)2]; inorganic complex; cancer cell lines; anti-proliferation

Suggested Citation: Guney S, Ergun S, Matic I, Petrovic N, Stanojkovic T. The Investigation of Anti-Proliferative Effects of [Ag2(sac)2(dap)2] Complex on Different Types of Cancer. Middle Black Sea Journal of Health Science, 2020; 6(1):54-58

\section{Address for correspondence/reprints:}

Sercan Ergun

E-mail: sercanergun@odu.edu.tr

Telephone number: +90 (452) $2265214-5251$

DOI: $\quad 10.19127 / \mathrm{mbsjohs.691369}$

ORCID-ID 0000-0002-6733-9848 


\section{Introduction}

Saccharin is an organic compound with a melting point of $225-227{ }^{\circ} \mathrm{C}$, systematically called 1,2benzisothiazol-3 (2H) -one 1,1-dioxide or osulfobenzimide. Saccharin, which is 500 to 700 times sweeter than sugar, is not metabolized in the body and it is used as a reliable artificial sweetener for diabetics because of this feature. The use of saccharin as an antidote to metal poisoning, its features listed above and its use in the food, beverage, toothpaste, mouthwash and pharmaceutical industries are increasing the importance of studies conducted on saccharin (Baran and Yilmaz, 2006).

In addition, saccharin is a highly preferred ligand in recent years since it has a multi-functional ligand feature. Sodium saccharinate, the sodium salt of saccharin, is highly soluble in water $(830 \mathrm{~g} / \mathrm{L}$ at 20 ${ }^{\circ} \mathrm{C}$ ) and is suitable for use both as a ligand and as a sweetener. When sodium saccharinate is used as the ligand, the saccharinate anion recovered in the solution has both negatively charged $\mathrm{N}$ atoms and $\mathrm{CO}$ and $\mathrm{SO} 2$ groups and is coordinated to metals with all these donor parts. The presence of anti-bacterial and anti-carcinogenic effects of metal saccharin complexes synthesized in the literature also increases the importance of studies on these complexes. In recent years, $\mathrm{Pt}$ (II) and Pd (II) complexes with mixed ligands containing saccharinates were synthesized and their anticancer effects were determined (Henderson et al., 1999; Yilmaz et al., 2018; Ari et al. 2013)

Since cisplatin complexes, which are the first and most widely used inorganic complex in cancer treatment, have serious side effects, the researchers focused on the synthesis of new metal complexes that are more effective in cancer cells (Florea and Büsselberg, 2011). In our previous study, [Ag2(sac)2(dap)2] complex was successfully synthesized and the chemical structure of it was characterized via spectroscopic techniques. In this study, anti-proliferative effects of [Ag2(sac)2(dap)2] complex on different types of cancer cell lines were investigated.

\section{Methods}

This study is designed as experimental in vitro study. HeLa (cervical cancer), PC-3 (prostate cancer), DU-145 (prostate cancer), A549 (non-small cell lung cancer), K562 (chronic myeloid leukemia) and MRC5 (normal lung fibroblast) cell lines were placed overnight in the incubator after changing the medium of the cell lines. Then, the cells in the centrifuge tube containing a mixture of RPMI-1640, 10\% FCS and $1 \%$ penicillin + streptomycin were rotated at 1000 rpm and $4{ }^{\circ} \mathrm{C}$ for 5 minutes. The supernatant was discarded and the cells in the bottom were planted in flasks with medium and placed in an incubator containing $5 \% \mathrm{CO} 2$ and $100 \%$ humidity at $37^{\circ} \mathrm{C}$. The flasks in the incubator were checked by an inverted microscope during the incubation period and the proliferation of the cells was observed, provided that the cells were not displaced for the first two days. Aged media were emptied with the help of a pipette and renewed every 2-3 days with a medium containing $0.1 \mathrm{~mL}$ penicillin + streptomycin, $1 \mathrm{~mL}$ FCS and 8.9 mL RPMI-1640. After the cells covered the flask base by $85-90 \%$, the cells remaining in the flask base were counted with trypan blue staining method, the number of viable cells in $1 \mathrm{ml}$ was determined and the cells seeded in 96-well containers with $1 \times 104$ cells per well. In order to determine the effect of the complex on the proliferation of cells and the level of inhibitory concentration 50\% (IC50), the cells were treated with concentrations of $0,250,500$, 750,1000 and $1250 \mu \mathrm{M}$ of $[\mathrm{Ag} 2$ (sac)2(dap)2] complex for 24 and 48 hours. Also, the cells were treated with cisplatin as a control in order to compare anti-proliferative effects of [Ag2(sac)2(dap)2] complex. The primary output measurements of the study were IC50 values of complex on specified cell lines.

MTT method is based on the conversion of the tetrazolium ring of the compound MTT (3- (4,5Dimethylthiazol-2-Yl) -2,5-Diphenyltetrazolium Bromide) into formazan by a mitochondrial enzyme, succinate dehydrogenase enzyme in the cells (live and mitochondrial functions are intact). Pale yellow MTT in the living cell turns into a dark blue-purple insoluble formazan product as a result of the destruction of the tetrazolium ring. Thus, the cells that live and have intact mitochondrial function are stained in purple, whereas the cells that are dead and have impaired mitochondrial function are not stained. After the cells are dissolved with organic solvent (eg isopropanol, DMSO, etc.), the color intensity of the formazan solution is measured spectrophotometrically at $590 \mathrm{~nm}$. The reduction of MTT occurs only in cells that are metabolically active, and the level of this activity is measured by the viability of the cells. MTT solution was obtained by dissolving $5 \mathrm{mg}$ of MTT in $1 \mathrm{~mL}$ of $1 \mathrm{x}$ CMF-PBS. The solution was stored in the dark at $+4^{\circ} \mathrm{C}$. Cultured cells were treated with [Ag2(sac)2(dap)2] complex and cisplatin to each cell line at specified concentrations separately. $20 \mu \mathrm{L}$ of MTT solution was added to each well of 96-well microplate containing incubated cells. The cells were kept in an orbital shaker outside the incubator at $150 \mathrm{rpm}$ for 5 
minutes. The cells were incubated for 3 hours in 5\% $\mathrm{CO} 2$ incubator at $37^{\circ} \mathrm{C}$. Supernatant liquid in the wells was discarded and $100 \mu \mathrm{L}$ DMSO was added to the wells. Again, the cells were kept in an orbital shaker outside the incubator at $150 \mathrm{rpm}$ for 5 minutes. The intensity of resulting color was measured at 590 $\mathrm{nm}$ (against the reference wavelength of $670 \mathrm{~nm}$ ) on a microplate reader spectrophotometer. The formula specified was used to calculate \% of cell viability: [\% of cell viability $=($ total number of cells-total number of dead cells)/total number of cells x 100] (Tam et al., 2011).

SPSS v24 (IBM SPSS Statistics for Windows, Version 24, IBM Corp., Armonk, NY, USA) was used in statistical analysis to evaluate the antiproliferative effect of [Ag2(sac)2(dap)2] complex on HeLa, PC-3, DU-145, A549, K562 and MRC-5 cell lines. As statistical analysis, Student's t test was used for binary comparisons and one-way ANOVA test was used for more than two comparisons.

\section{Results}

Anti-proliferative effects of [Ag2(sac)2(dap)2] complex on HeLa, PC-3, DU-145, A549, K562 and MRC-5 cell lines were investigated.

For this purpose, IC 50 values of [Ag2(sac)2(dap)2] complex on cell lines was determined by MTT method (Table 1). According to this analysis, IC 50 value of [Ag2(sac)2(dap)2] complex was $19.53 \pm 1.74 \mu \mathrm{M}$ for HeLa cell line, $17.14 \pm 1.41 \mu \mathrm{M}$ for PC-3 cell line, $18.56 \pm 4.04$ for DU 145 cell line, $17.93 \pm 1.06 \mu \mathrm{M}$ for A549 cell line, $3.18 \pm 0.04 \mu \mathrm{M}$ for $\mathrm{K} 562$ cell line and $7.25 \pm 1.00 \mu \mathrm{M}$ for MRC-5 cell line. Also, IC 50 values of cisplatin on cell lines was determined in order to compare with [Ag2(sac)2(dap)2] complex. IC 50 value of cisplatin was $4.00 \pm 0.47 \mu \mathrm{M}$ for HeLa cell line, $12.29 \pm 1.60$ $\mu \mathrm{M}$ for PC-3 cell line, $5.05 \pm 0.65$ for DU 145 cell line, $12.74 \pm 1.26 \mu \mathrm{M}$ for A549 cell line, $5.90 \pm 0.59$ $\mu \mathrm{M}$ for $\mathrm{K} 562$ cell line and $5.91 \pm 0.32 \mu \mathrm{M}$ for MRC5 cell line.

Moreover, schematic representation of inhibitory concentrations of [Ag2(sac)2(dap)2] complex on cell lines in comparison with cisplatin was presented in Figure 1.

As can be seen, IC 50 values of [Ag2(sac)2(dap)2] complex on all cell lines were higher when compared to IC 50 value of cisplatin, except K562. Only in K562 cell line, IC 50 of [Ag2(sac)2(dap)2] complex was lower than IC 50 of cisplatin. This means that [Ag2(sac)2(dap)2] complex shows more antiproliferative effect than cisplatin on chronic myeloid leukemia cells.

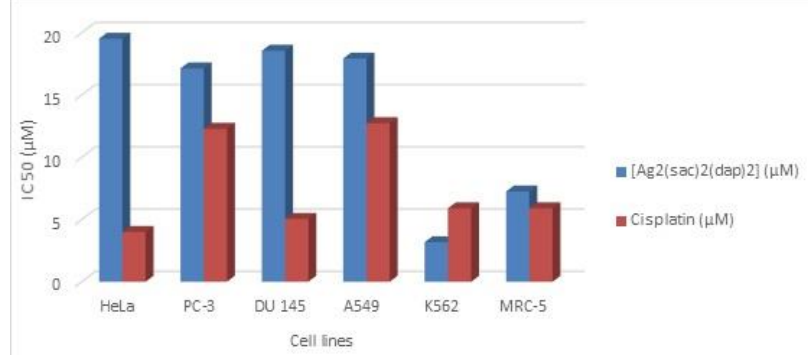

Figure 1. Schematic representation of inhibitory concentrations of [Ag2(sac)2(dap)2] complex on cell lines in comparison with cisplatin

Table 1. Inhibitory concentrations of $\left[\mathrm{Ag}_{2}(\mathrm{sac})_{2}(\mathrm{dap})_{2}\right]$ complex and cisplatin on cell lines

\begin{tabular}{|c|c|c|c|}
\hline & & \multicolumn{2}{|c|}{$\operatorname{IC50}(\mu \mathrm{M})$} \\
\hline & & {$\left[\mathrm{Ag}_{2}(\mathbf{s a c})_{2}(\mathrm{dap})_{2}\right]$} & Cisplatin \\
\hline \multirow{6}{*}{$\begin{array}{l}\stackrel{\mathscr{\Xi}}{\Xi} \\
\overline{\bar{d}}\end{array}$} & HeLa & $19.53 \pm 1.74$ & $4.00 \pm 0.47$ \\
\hline & PC-3 & $17.14 \pm 1.41$ & $12.29 \pm 1.60$ \\
\hline & DU 145 & $18.56 \pm 4.04$ & $5.05 \pm 0.65$ \\
\hline & A549 & $17.93 \pm 1.06$ & $12.74 \pm 1.26$ \\
\hline & K562 & $3.18 \pm 0.04$ & $5.90 \pm 0.59$ \\
\hline & MRC-5 & $7.25 \pm 1.00$ & $5.91 \pm 0.32$ \\
\hline
\end{tabular}

\section{Discussion}

Mostly, metals are fundamental components of cells chosen by nature. They are commonly placed in the enzyme catalytic region and are included in various biological pathways, from the exchange of electrons to structural and catalysis functions. They are widely utilized in cellular processes. Such metals are silver, gallium, cobalt, zinc, strontium, vanadium, copper and manganese, which are needed in trace quantities to activate catalytic activities (Mourino et al., 2012). Therefore, a homeostasis between cellular requirement and the amount present in the body is crucial for the normal physiological condition. In contrast, metals, including cadmium, nickel, arsenic and chromium, can trigger tumor formation and thus are less useful to the body. These boundaries have encouraged a study for platinum-based complexes showing higher selectivity, lower toxicity and a wider spectrum of function (Benedetti et al., 2011). Platinum (II) complexes like oxaliplatin and carboplatin, also other platinum analogs, are the products of this study. Other metal complexes containing ions like copper, gold and zinc (II) chelating agents have taken significant attention as anti-proliferative molecules. Lately, the chemistry of gold-based and ruthenium complexes has taken intensive examination, owing to renewed attention in giving an alternate to cisplatin and their encouraging 
cytotoxic and probable anti-proliferative characteristics (Ndagi et al., 2017).

Newly, cytotoxic characteristics of silver (I) compounds have taken attention thank to the fact that most silver (I) compounds have been observed to show a better cytotoxic effect than cisplatin with comparatively lower toxicity and higher selectivity against tumor cells. In an in vitro research performed to evaluate the cytotoxic features of silver(I) compounds toward tumoral B16 (murine melanoma) and non-tumoral 10T1/2 (murine fibroblast) cell lines, silver compounds containing hydroxymethylene group presented higher cytotoxic activity for B16 (murine melanoma) than cisplatin $\mathrm{AgSD}$ and AgNO3. These compounds were detected to show comparatively lower toxicity against nontumoral 10T1/2. Correspondingly, a research group studying to define the anticancer characteristics of silver (I) and gold (I) N-heterocyclic carbene compounds showed that these complexes displayed similar anticancer effect on H460 lung cancer cell line when compared to cisplatin. Moreover, silver complexes were synthesized from 2,6-disubstituted pyridine ligands. The complexes and the ligands were assessed in vitro in lung adenocarcinoma (A549), hepatocellular carcinoma (HepG2), breast adenocarcinoma (MCF7) and colon carcinoma (HT29) via MMT method by comparing with reference agent doxorubicin. All synthesized compounds displayed greater significant activity than the corresponding ligands and most of synthesized silver compounds showed magnificent cytotoxic activity against cancer cell lines in comparison with doxorubicin (Siciliano et al., 2011; Ali et al., 2013; Kalinowska-Lis et al., 2016). All these features made silver compounds potential metal compounds to be used for chemotherapy in future.

In this study, anti-proliferative effects of [Ag2(sac)2(dap)2] complex on HeLa, PC-3, DU-145, A549, K562 and MRC-5 cell lines were investigated. According to MTT analysis results, IC 50 value of [Ag2(sac)2(dap)2] complex was $19.53 \pm 1.74 \mu \mathrm{M}$ for HeLa cell line, $17.14 \pm 1.41 \mu \mathrm{M}$ for PC-3 cell line, $18.56 \pm 4.04$ for DU 145 cell line, $17.93 \pm 1.06 \mu \mathrm{M}$ for A549 cell line, $3.18 \pm 0.04 \mu \mathrm{M}$ for K562 cell line and $7.25 \pm 1.00 \mu \mathrm{M}$ for MRC-5 cell line. Also, IC 50 values of cisplatin on cell lines was determined in order to compare with [Ag2(sac)2(dap)2] complex. IC 50 value of cisplatin was $4.00 \pm 0.47 \mu \mathrm{M}$ for $\mathrm{HeLa}$ cell line, $12.29 \pm 1.60 \mu \mathrm{M}$ for PC-3 cell line, $5.05 \pm$ 0.65 for DU 145 cell line, $12.74 \pm 1.26 \mu \mathrm{M}$ for A549 cell line, $5.90 \pm 0.59 \mu \mathrm{M}$ for K562 cell line and 5.91 $\pm 0.32 \mu \mathrm{M}$ for MRC- 5 cell line.
As similar to data of the literature about especially different silver complexes, anti-proliferative activity of [Ag2(sac)2(dap)2] complex on HeLa, PC-3, DU145, A549, K562 and MRC-5 cell lines was considerably high. Especially, IC 50 of [Ag2(sac)2(dap)2] complex on K562 was lower than IC 50 of cisplatin. This means that [Ag2(sac)2(dap)2] complex shows more anti-proliferative effect than cisplatin on chronic myeloid leukemia cells.

\section{Conclusion}

Cytotoxic features of silver compounds have taken attention thank to the fact that most silver compounds have been observed to show a better cytotoxic effect than cisplatin with comparatively lower toxicity and higher selectivity against tumor cells. In our study, as similar to data of the literature about especially different silver complexes, cytotoxic activity of [Ag2(sac)2(dap)2] complex on HeLa, PC-3, DU-145, A549, K562 and MRC-5 cell lines was noticeably high. Especially, IC 50 of [Ag2(sac)2(dap)2] complex on K562 was lower than IC 50 of cisplatin. This means that [Ag2(sac)2(dap)2] complex shows more anti-proliferative effect than cisplatin on chronic myeloid leukemia cells. Even if, antiproliferative activity of [Ag2(sac)2(dap)2] complex is needed to be confirmed with more complex experimental procedures. If verified, [Ag2(sac)2(dap)2] complex may be possible to be used as a treatment option especially for chronic myeloid leukemia.

Ethics Committee Approval: Ethics committee approval was not required because this is an in vitro study.

Peer-review: Externally peer-reviewed.

Author Contributions: Concept-S.G, S.E; DesignS.E, I.M, N.P; Supervision-S.G, T.S; Funding-None Materials-S.G, S.E; Data Collection/Data ProcessS.G, S.E, I.M, N.P; Analyze or Comment-S.E, I.M, N.P; Literature Scanning-S.G, S.E; Write of PaperS.E; Critical Review-S.G, S.E.

Conflict of Interest: No conflict of interest was declared by the authors.

Financial Disclosure: This study has been financed partially by Scientific Research Projects Commission of Ordu University (Project number: A-1842 and AR1650). 


\section{References}

Ali KA, Abd-Elzaher MM and Mahmoud K. Synthesis and anticancer properties of silver (I) complexes containing 2, 6-Bis (substituted) pyridine derivatives. Int J Med Chem 2013; 256836.

Ari F, Aztopal N, Icsel C, Yilmaz VT, Guney E, Buyukgungor O, Ulukaya E. Synthesis, structural characterization and cell death-inducing effect of novel palladium (II) and platinum (II) saccharinate complexes with 2-(hydroxymethyl) pyridine and 2-(2-hydroxyethyl) pyridine on cancer cells in vitro. Bioorgan Med Chem 2013;21(21): 64276434.

Baran EJ, Yilmaz VT. Metal complexes of saccharin. Coordin Chem Rev 2006; 250(15-16): 1980-1999.

Benedetti BT, Peterson EJ, Kabolizadeh P, Martínez A, Kipping R, Farrell NP. Effects of noncovalent platinum drug-protein interactions on drug efficacy: use of fluorescent conjugates as probes for drug metabolism. Mol Pharmaceut 2011; 8(3): 940-948.

Florea AM, Büsselberg D. Cisplatin as an anti-tumor drug: cellular mechanisms of activity, drug resistance and induced side effects. Cancers 2011; 3(1): 1351-1371.

Henderson W, Nicholson BK, McCaffrey LJ. Platinum (II) and palladium (II) saccharinate complexes. Inorg Chim Acta 1999; 285(1): 145148.

Kalinowska-Lis U, Felczak A, Checinska L, Szabłowska-Gadomska I, Patyna E, Malecki M, et al. Antibacterial activity and cytotoxicity of silver (I) complexes of pyridine and (Benz) imidazole derivatives. X-ray crystal structure of [Ag (2, 6-di (CH2OH) py) 2] NO3. Molecules 2016; 21(2): 87.

Mourino V, Cattalini JP, Boccaccini AR. Metallic ions as therapeutic agents in tissue engineering scaffolds: an overview of their biological applications and strategies for new developments. J R Soc Interface 2012; 9(68): 401-419.

Ndagi U, Mhlongo N, Soliman ME. Metal complexes in cancer therapy-an update from drug design perspective. Drug Des Dev Ther 2017; 11: 599.

Siciliano TJ, Deblock MC, Hindi KM, Durmus S, Panzner MJ, Tessier CA, Youngs WJ. Synthesis and anticancer properties of gold (I) and silver (I) $\mathrm{N}$-heterocyclic carbene complexes. J Organomet Chem 2011; 696(5): 1066-1071.

Tam JCW, Lau KM, Liu CL, To MH, Kwok HF, Lai KK, San Lau CB. The in vivo and in vitro diabetic wound healing effects of a 2-herb formula and its mechanisms of action. J Ethnopharm 2011; 134(3): 831-838.
Yilmaz VT, Icsel C, Turgut OR, Aygun M, Erkisa M, Turkdemir MH, Ulukaya E. Synthesis, structures and anticancer potentials of platinum (II) saccharinate complexes of tertiary phosphines with phenyl and cyclohexyl groups targeting mitochondria and DNA. Eur J Med Chem 2018; 155: 609-622. 